\title{
The 1, 2, 3, 4 of carcinoid heart disease: Comprehensive cardiovascular imaging is the mainstay of complex surgical treatment (Review)
}

\author{
DINU VALENTIN BALANESCU ${ }^{1}$, TEODORA DONISAN ${ }^{1}$, JUAN LOPEZ-MATTEI ${ }^{1}$, SAAMIR HASSAN ${ }^{1}$, \\ PETER KIM $^{1}$, ARVIND DASARI ${ }^{2}$, DANIEL HALPERIN ${ }^{2}$, JAMES YAO ${ }^{2}$, BISWAJIT KAR ${ }^{3}$, \\ IGOR GREGORIC $^{3}$, SERBAN MIHAI BALANESCU ${ }^{4}$ and CEZAR ILIESCU $^{1}$
}

\begin{abstract}
Departments of ${ }^{1}$ Cardiology and ${ }^{2}$ Gastrointestinal Medical Oncology, The University of Texas MD Anderson Cancer Center;
${ }^{3}$ Center for Advanced Heart Failure, The University of Texas Health Science Center at Houston,

Houston, TX 77030, USA; ${ }^{4}$ Department of Cardiology, Elias Emergency University Hospital,

'Carol Davila' University of Medicine and Pharmacy, Bucharest 011134, Romania
\end{abstract}

Received August 30, 2018; Accepted October 10, 2018

DOI: $10.3892 / 01.2018 .9732$

\begin{abstract}
Carcinoid heart disease (CHD) is a rare complication of neuroendocrine tumors, most commonly involving the tricuspid and pulmonary valves. The mitral and aortic valves can also be affected, albeit rarely, in certain circumstances such as the presence of a patent foramen ovale. Transthoracic echocardiogram is generally considered the key imaging modality, but cardiac magnetic resonance can add valuable information, particularly in the assessment of pulmonary valve function or multivalvular disease. Previously, surgical management of CHD carried high mortality, as a result of less advanced surgical techniques and of late intervention, reserved for cases of severely symptomatic heart failure. Modern approaches are associated with significantly improved survival rates, even in multivalvular, complex cases. Valve replacement can provide survival benefits in patients with $\mathrm{CHD}$, but the optimal timing for the intervention is uncertain, with data suggesting a trend of improved survival with earlier intervention. A comprehensive imaging assessment may contribute to establishing optimal surgical timing. This approach may shift the main driver of mortality from the cardiac involvement to the primary malignancy and lead to improved outcomes. We present a series of imaging findings in CHD patients who have successfully undergone simultaneous surgical replacement with bioprosthetic valves of 1 to 4 heart valves. The surgical decision in these patients was based on a multimodality cardiovascular approach, including trans-
\end{abstract}

Correspondence to: Dr Serban Mihai Balanescu, Department of Cardiology, Elias Emergency University Hospital, 'Carol Davila' University of Medicine and Pharmacy, 17 Marasti Boulevard, Bucharest 011134, Romania

E-mail: smbala99@hotmail.com

Key words: echocardiography, carcinoid heart disease, cardiac surgery, magnetic resonance imaging, neuroendocrine tumors thoracic and transesophageal echocardiography and cardiac magnetic resonance. The patients had uncomplicated postoperative courses, significant symptomatic relief from heart failure symptoms, and there was no cardiovascular mortality. Early recognition of CHD with a multimodality approach may improve outcome, even in complex cases. Bioprosthetic valves are generally preferred in CHD due to decreased need for anticoagulation, despite concern for premature degeneration. A collaboration between the Oncology and Cardiology teams is essential for the long-term management of CHD patients.

\section{Contents}

1. Introduction

2. Case series

3. Diagnosing carcinoid heart disease

4. Treatment, surgical outcomes and disease progression

\section{Introduction}

Neuroendocrine tumors (NETs, also named carcinoids) are rare neoplasms that most commonly originate in the gastrointestinal tract (1), with an incidence of 2.5-5 cases per 100,000 population (2). Approximately 20-30\% of these patients present with carcinoid syndrome, which can occur regardless of the presence of metastatic disease (3). Carcinoid heart disease (CHD) is frequently associated with carcinoid syndrome and is responsible for substantial morbidity and mortality $(4,5)$, with a 2 -year survival of $~ 10 \%$ following the onset of advanced heart failure symptoms (6). CHD is characterized by plaque-like, fibrous endocardial thickening of the heart valves, mainly in the right heart; mitral and aortic valves are very rarely involved. There is considerable variation regarding the screening and management of $\mathrm{CHD}$ (7). A recent expert consensus (2) mentions transthoracic echocardiogram (TTE) as the key modality in the evaluation of CHD, but 

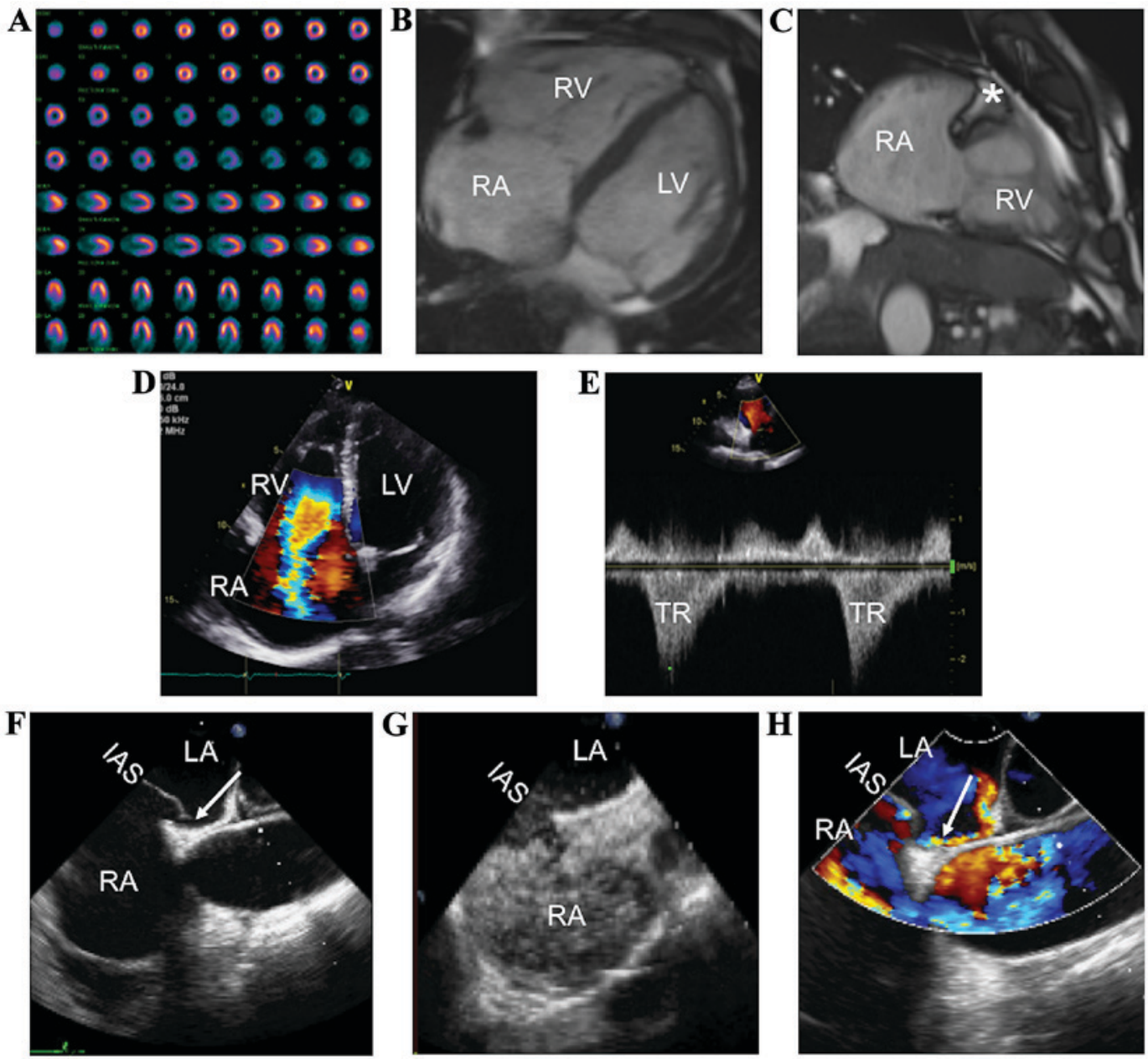

Figure 1. CHD in a patient who underwent tricuspid valve replacement. (A) Normal nuclear perfusion stress test. (B and C) Cardiac magnetic resonance imaging with evidence of severe RA and RV dilation, and TV thickening (*) with severe TR. (D and E) Preoperative transthoracic echocardiography showing severe TR. Preoperative transesophageal echocardiography revealing persistent foramen ovale (F, arrow) with contrast $(\mathrm{G})$ and Doppler studies (H, arrow) CHD, carcinoid heart disease; RA, right atrium; RV, right ventricle; TV, tricuspid valve; TR, tricuspid regurgitation; IAS, interatrial septum; LV, left ventricle.

cardiac magnetic resonance $(\mathrm{CMR})$ imaging can be a valuable adjunct (8). Cardiac valve replacement is the only intervention proven to improve survival in CHD (6). We present a series of imaging findings in CHD patients approved by the MD Anderson Catheterization Laboratory Registry at The University of Texas MD Anderson Cancer Center (Houston, TX, USA) with surgical replacement of 1 to 4 heart valves.

\section{Case series}

Case 1. A 57-year-old male with a history of heart failure due to severe tricuspid regurgitation caused by CHD presented with chest pain, dyspnea, and bilateral lower extremity edema. Nuclear perfusion stress test was negative for ischemia (Fig. 1A). CMR imaging 6 months prior to the current presentation revealed a severely dilated right atrium and right ventricle (Fig. 1B), with a small and fixed medial tricuspid valve leaflet and severe tricuspid regurgitation (Fig. 1C). Mild mid-myocardial delayed enhancement in the proximal inferolateral wall suggestive of non-ischemic cardiomyopathy was also noted. Surgical tricuspid valve replacement was considered. On preoperative TTE, the right atrium and right ventricle were severely dilated, with severe tricuspid regurgitation (Fig. 1D and 1E). An interatrial shunt was observed on TEE (Fig. 1F, arrow), documented with contrast injection (Fig. 1G) and Doppler color (Fig. 1H, arrow). The patient received a 31-mm Epic bioprosthetic tricuspid valve (St. Jude Medical, Inc., St. Paul, MN, USA) and had an uneventful postoperative course, with significantly improved heart failure symptoms. Good functional status was maintained at the last follow-up, 8 months after the surgery.

Case 2. A 40-year-old male with a 3-year history of CHD presented for increasing dyspnea, abdominal distention, and lower extremity edema. CMR two years before the current presentation showed severe right atrium and right ventricle dilation (Fig. 2A), dilated tricuspid annulus, immobile tricuspid leaflets with no coaptation, severe tricuspid regurgitation (Fig. 2B), mild pulmonic regurgitation, and a pulmonic stenotic jet (Fig. 2C, arrow). Surgical replacement of the tricuspid and pulmonic valves was considered. Preoperative TTE showed severely dilated right atrium and right ventricle (Fig. 2D), with severe tricuspid regurgitation (Fig. 2E) and pulmonic regurgitation (Fig. 2F). The patient underwent surgical tricuspid and pulmonic valves replacement with Epic bioprosthetic valves (29 and $23 \mathrm{~mm}$, 

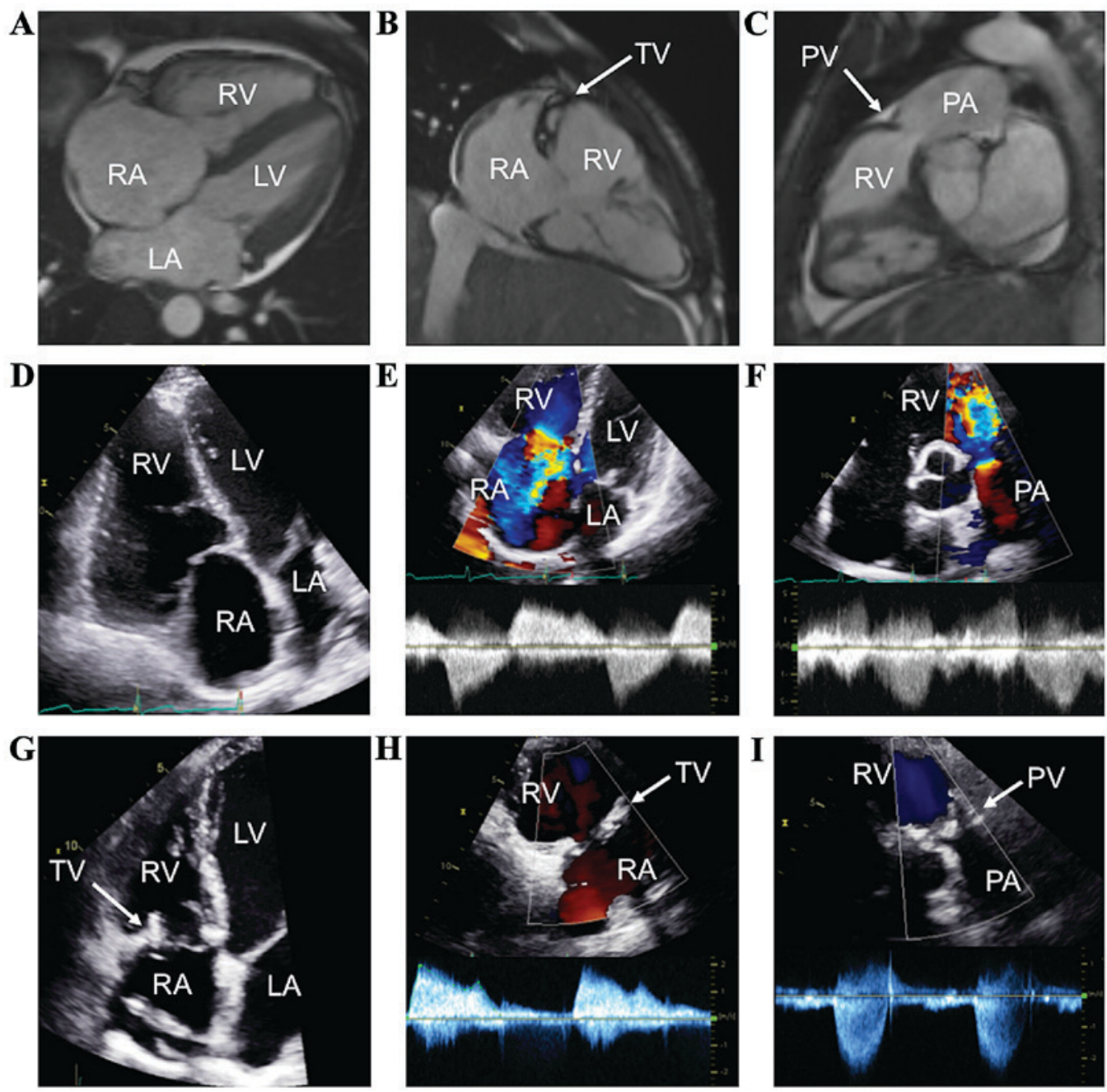

Figure 2. CHD in a patient who underwent simultaneous tricuspid and pulmonary valve replacement. (A and B, arrow) Cardiac magnetic resonance imaging revealing severely diseased TV, and (C, arrow) mild carcinoid involvement of the PV. (D and E) Preoperative TTE with severe tricuspid and (F) pulmonary regurgitation. (G-I) Postoperative TTE showing bioprosthetic TV and PV, with normal function. CHD, carcinoid heart disease; TV, tricuspid valve; LA, left atrium; PV, pulmonary valve; LV, left ventricle; PA, pulmonary artery; TTE, transthoracic echocardiography; RA, right atrium; RV, right ventricle.

respectively; St. Jude Medical, Inc.), without perioperative complications and with symptoms resolution. On postoperative TTE, the right ventricular size normalized (Fig. 2G) and the bioprosthetic tricuspid and pulmonic valves were functioning normally (Fig. 2H and I). The patient was free of heart failure symptoms at 13 months post-surgery.

Case 3. A 78-year-old man with CHD and severe tricuspid regurgitation diagnosed 2 years prior to the current admission presented with mild dyspnea. TTE revealed enlarged right atrium and right ventricle (Fig. 3A), severe tricuspid regurgitation (Fig. 3B), moderate pulmonic regurgitation, and moderate aortic regurgitation. CMR showed severe right atrium and right ventricle enlargement (Fig. 3C and D), immobile and thickened tricuspid valve leaflets with severe tricuspid regurgitation, and thickened aortic valve leaflets, with moderate aortic regurgitation. In the presence of cardiac symptoms, the decision was made to replace the tricuspid, pulmonic, and aortic valves in one surgery. A 23-mm Labcor TBLP Supra bioprosthetic aortic valve (Labcor Laboratõrios, Belo Horizonte, Brazil), a 29-mm Epic pulmonary bioprosthetic valve, and a 29-mm Epic tricuspid bioprosthetic valve (both from St. Jude Medical, Inc.) were implanted. After a successful surgery with no perioperative complications and with symptomatic relief, TTE showed normal right atrial and right ventricular sizes (Fig. 3E), without residual tricuspid regurgitation (Fig. 3F). CMR performed postoperatively revealed normal right heart sizes (Fig. 3G), with visible bioprosthetic tricuspid valve (Fig. 3G and $\mathrm{H}$ arrows), aortic valve (Fig. 3I and J, thin arrows), and pulmonic valve (Fig. 3J, thick arrow). Good functional status was reported 11 months following the intervention.

Case 4. A 54-year-old female with a history of neuroendocrine tumor and subsequent concern for CHD presented with orthopnea, paroxysmal nocturnal dyspnea, and lower extremity edema. While CMR 9 months prior showed normal cardiac chamber sizes (Fig. 4A) and mild-to-moderate aortic regurgitation and mitral regurgitation (Fig. 4B), current TTE confirmed rapid progression of her valvular heart disease, with right ventricular volume overload, thickened mitral and aortic valves (Fig. 4C, zoom on the mitral valve), severe tricuspid regurgitation (Fig. 4D), severe pulmonic regurgitation (Fig. 4E), severe eccentric mitral regurgitation (Fig. 4F, arrow), severe mitral stenosis (mean gradient of 

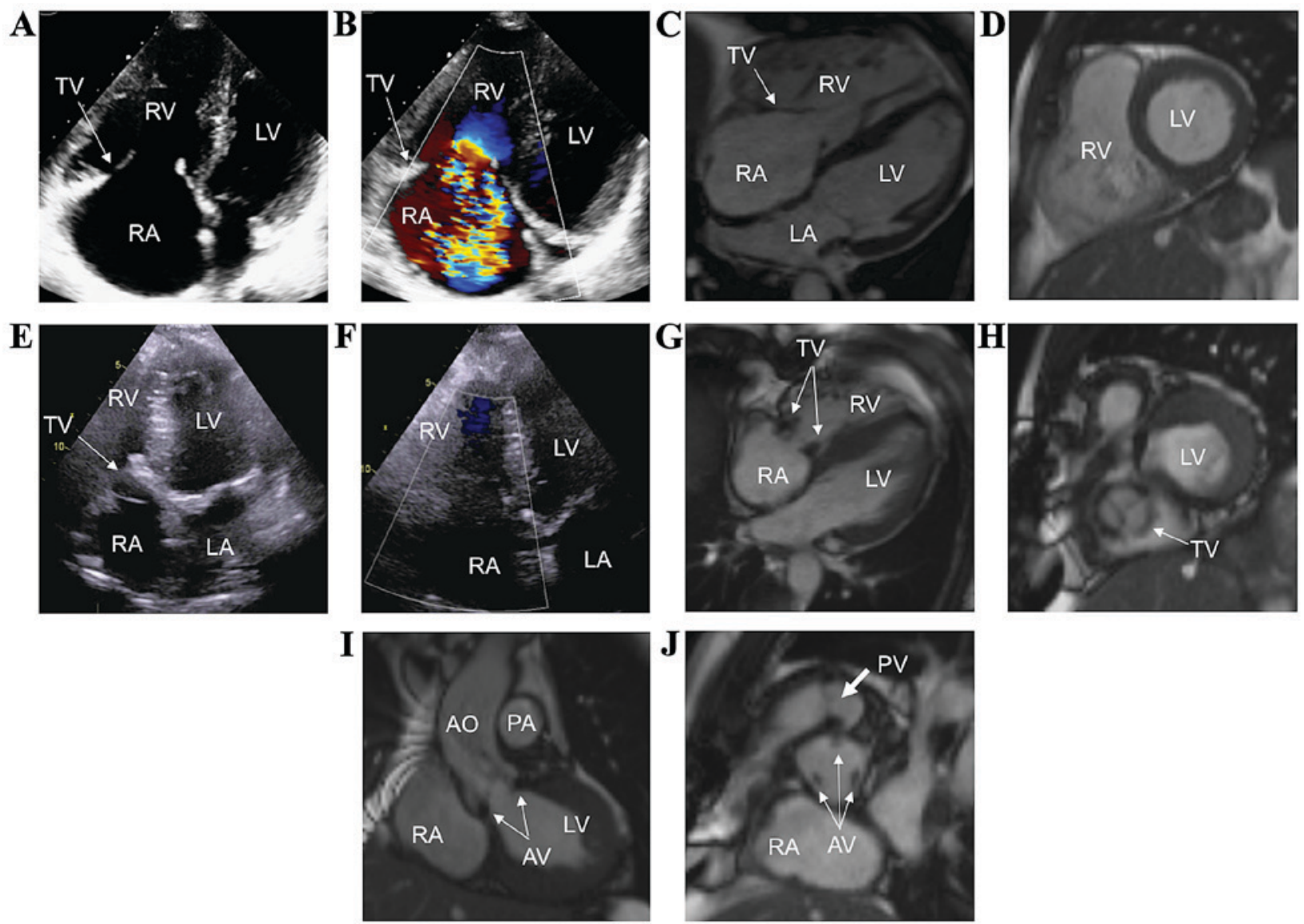

Figure 3. CHD in a patient who underwent simultaneous tricuspid, pulmonic, and aortic valve replacement. (A and B) TTE showing severe TR. (C and D) Preoperative CMR imaging illustrating dilated right heart chambers and severe TR. (E and F) Postoperative TTE showing the bioprosthetic TV, without residual TR. Postoperative CMR imaging showing the bioprosthetic TV (G and H, arrows), aortic valve (I and J, thin arrows), and pulmonary valve (J, thick arrow) in different views. CHD, carcinoid heart disease; TTE, transthoracic echocardiography; TR, tricuspid regurgitation; CMR, cardiac magnetic resonance; TV, tricuspid valve; AO, ascending aorta; LA, left atrium; LV, left ventricle; PA, pulmonary artery; RA, right atrium; RV, right ventricle.

$13.1 \mathrm{mmHg}$ ), and severe aortic regurgitation (Fig. 4G). She successfully underwent surgical replacement of the aortic, mitral, tricuspid, and pulmonic valves with Epic bioprosthetic valves (aortic valve, $21 \mathrm{~mm}$; pulmonary valve, $21 \mathrm{~mm}$; mitral valve, $29 \mathrm{~mm}$; and tricuspid valve, $29 \mathrm{~mm}$; St. Jude Medical, Inc.) during the same procedure, with an excellent postoperative course. TTE on postoperative follow-up showed normal biventricular size and function, with normally functioning bioprostheses (Fig. 4H and I, zoom on the mitral valve). No heart failure symptoms were present at 1-year follow-up.

\section{Diagnosing carcinoid heart disease}

Despite progress in the medical and surgical management of patients with carcinoid disease, CHD remains a major cause of morbidity and mortality (4). It is believed that CHD most commonly involves the right side of the heart because of the inactivation of humoral substances by the lung (9). Left-sided involvement can occur in $<10 \%$ of patients with CHD (9), usually because of a concomitant right-to-left shunt such as a patent foramen ovale (7), or more rarely because of lung metastasis or high disease burden with unusually increased levels of circulating serotonin (10). The most common forms of valvular dysfunction noted in patients with CHD include tricuspid or pulmonic regurgitations, but concomitant pulmonic stenosis is also often found (9). Irreversible ventricular dysfunction can develop with valvular regurgitation before the onset of clinical symptoms, hence the need for careful serial observations and periodic serial cardiac imaging (11).

TTE is the main diagnostic tool used for the diagnosis and evaluation of CHD. However, if TTE is suboptimal, TEE can significantly enhance assessment of the mitral, aortic, and tricuspid valves. Advances in three-dimensional echocardiography and CMR can further delineate the pathophysiology and severity of valvular dysfunction. Assessment of myocardial strain is not well established in CHD, but may add value for the evaluation of right ventricular function $(12,13)$. CMR and CT may be particularly helpful in assessing the right heart, describing features of carcinoid valve disease, valve pathology, and right ventricular function (14). CMR also provides additional diagnostic accuracy in patients with multivalvular disease (11), who pose difficulties in determining disease severity, and may influence long-term management (15). Positron emission tomography may also add benefit by identifying cardiac metastases of the carcinoid tumor (15). Little information is available on the predictability of disease progression with imaging. Current data suggest that disease progression is mainly correlated with biochemical variables (e.g., serum 5-HIAA), rather than imaging or clinical findings (16). Post-valve replacement imaging assessment is not 

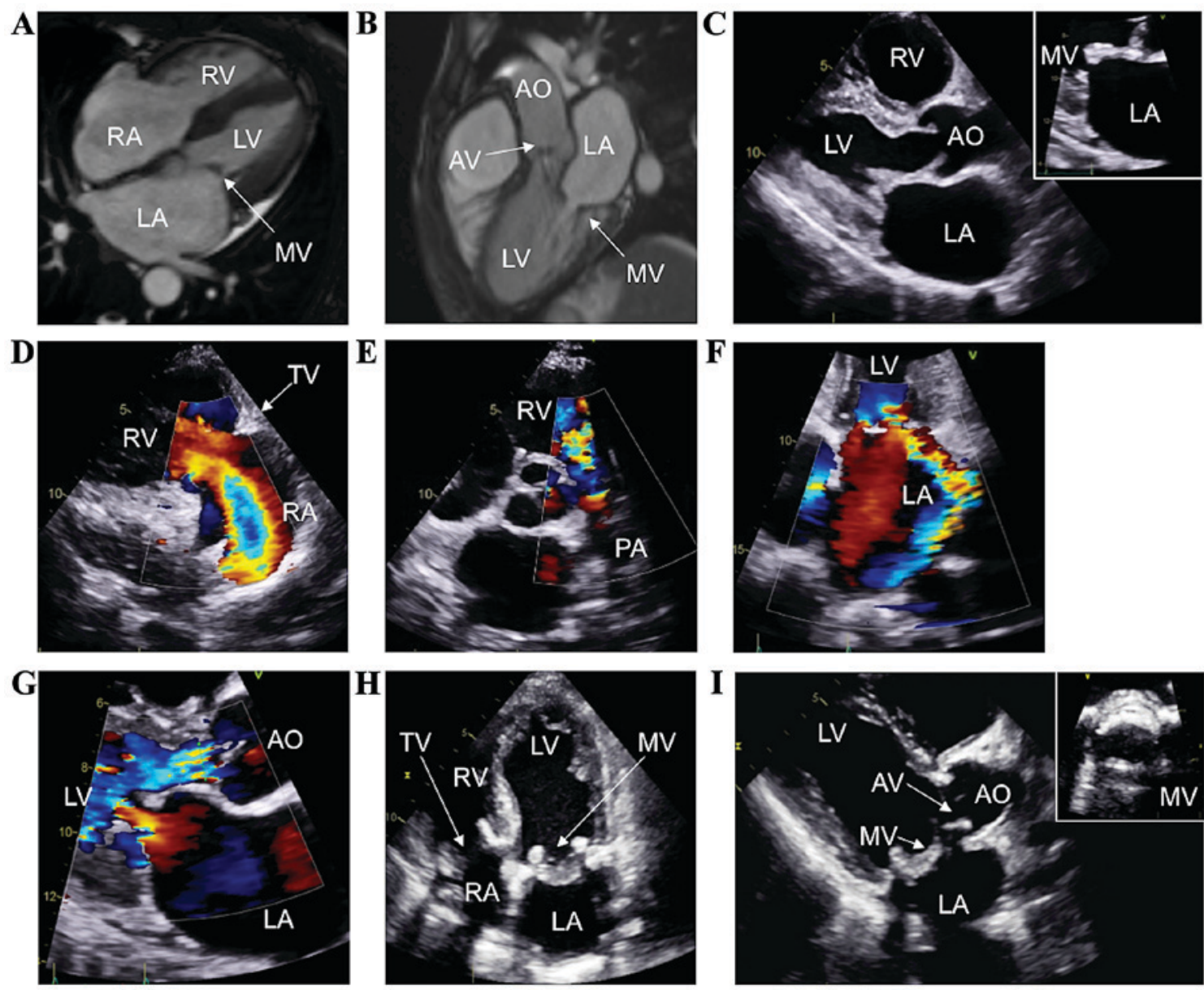

Figure 4. CHD in a patient who underwent simultaneous tricuspid, pulmonic, mitral, and aortic valve replacement. (A and B) Cardiac magnetic resonance imaging showing a normal right heart and moderate carcinoid involvement of the MV and AV. Preoperative TTE assessment showing thickening of the AV and MV (C, zoom on the MV), severe tricuspid (D) and pulmonary regurgitation (E), and moderate mitral (F) and aortic regurgitation (G). Postoperative TTE revealing the implanted bioprostheses of the tricuspid valve, MV, and AV (H-I, zoom on the MV). CHD, carcinoid heart disease; MV, mitral valve; AV, aortic valve; AO, ascending aorta; LA, left atrium; LV, left ventricle; PA, pulmonary artery; RA, right atrium; RV, right ventricle.

currently well documented and is generally performed based on clinical judgment.

\section{Treatment, surgical outcomes and disease progression}

The main objective of medical therapy in CHD is symptomatic improvement. In the presence of heart failure, treatment with diuretics and angiotensin-converting enzyme inhibitors $(17,18)$ is useful for symptomatic relief from volume overload. Somatostatin analogs work by reducing serum levels of serotonin, but have not been shown to prevent the development of CHD (19). Novel agents, such as everolimus (20) and telotristat (21), have shown benefit for carcinoid syndrome, but their role in the prevention of CHD has not yet been established (19).

Early diagnosis of CHD and regular follow-up is essential in order to identify patients likely to benefit from surgery, the only effective treatment for CHD (6). Standard indications for valve surgery apply, but mainly for patients whose metastatic carcinoid disease and syndrome are well controlled. There is no standard preoperative evaluation in these patients. The main driver of mortality in CHD patients is not carcinomatosis, but severe tricuspid regurgitation (22). Postoperative mortality is mainly driven by the disease, rather than procedure-related complications $(23,24)$. Because cardiac surgery for CHD had such high mortality rates, it was reserved for severely symptomatic patients with advanced cardiac disease. Late surgical referral has been proposed as a potential factor contributing to high postoperative rates (25). However, recent data suggest that there have been significant improvements in the postoperative mortality rates and median survival (13). Nowadays, there is a trend of earlier intervention, due to increased perioperative mortality in patients with severe heart failure and improvements in cardiac surgery (26). Cardiac surgery in CHD still has higher mortality rates than the general population, but survival and symptomatic relief are better than with medical treatment alone $(4,6,27)$. The feasibility of multiple valve replacement has been reported, leading to significant functional improvement $(28,29)$, as was the case with our patients.

Evidence suggests similar outcomes following either mechanical or bioprosthetic valve implantation (24). Bioprosthetic valves are increasingly used due to the decreased need for anticoagulation, despite concern for premature bioprosthetic degeneration as a consequence of the carcinoid tumor $(15,30,31)$. In cases of early prosthetic degeneration, reintervention with implantation of a new bioprosthetic valve is indicated (13). Of note, in a case series of 3 patients, stentless bioprostheses in the pulmonic position have been associated 
with premature restenosis requiring early reintervention (32). Transcatheter valve replacements have been described for the pulmonary (33) and tricuspid valves (34) in both native and bioprosthetic valves, but safety and outcome data are limited.

In conclusion, $\mathrm{CHD}$ has a wide spectrum of severity. A comprehensive imaging evaluation is necessary for an accurate preoperative assessment. Surgical treatment can be successfully attempted even in cases of multivalvular involvement, if appropriately guided by a multimodality imaging assessment and a multidisciplinary team. The management of patients with CHD is complex and involves a multidisciplinary effort (6). An integrative approach, involving both the Oncology and Cardiology teams, is recommended to achieve an accurate evaluation of the severity of the lesions, their clinical significance, and follow-up. Early recognition of CHD and prompt surgical intervention, before advanced heart failure has occurred, may improve the outcome of these patients. The accurate timing of surgery is crucial, but there are no clear guidelines on this matter, and published data suggest a trend of improved survival with earlier intervention. This approach may shift the main driver of mortality from the cardiac involvement to the primary malignancy and lead to improved outcomes.

\section{Acknowledgements}

The authors would like to thank the patients, physicians, and staff who assisted in this study.

\section{Funding}

No funding was received.

\section{Availability of data and materials}

The datasets used and/or analyzed during the current study are available from the corresponding author on reasonable request.

\section{Authors' contributions}

DVB, TD and SMB contributed to the conception and design of study. JLM, SH, PK, AD, DH, JY, BK, IG and CI were major contributors to the acquisition and analysis of the data. DVB, TD, SMB, JLM, SH, PK, AD, DH, JY, BK, IG and CI were responsible for drafting the study and revising it critically for important intellectual content. All authors read and approved the final version of study, and agree to be accountable for all aspects of the study in ensuring that questions related to the accuracy or integrity of any part of the study are appropriately investigated and resolved.

\section{Ethics approval and consent to participate}

The University of Texas MD Anderson Cancer Center Institutional Review Board (Houston, TX, USA) approved the study and waived the need for written informed consent, given the retrospective nature of the manuscript.

\section{Patient consent for publication}

Not applicable.

\section{Competing interests}

The authors declare that they have no competing interests.

\section{References}

1. Thanasupawat T, Hammje K, Adham I, Ghia JE, Del Bigio MR, Krcek J, Hoang-Vu C, Klonisch T and Hombach-Klonisch S: INSL5 is a novel marker for human enteroendocrine cells of the large intestine and neuroendocrine tumours. Oncol Rep 29: 149-154, 2013.

2. Davar J, Connolly HM, Caplin ME, Pavel M, Zacks J, Bhattacharyya S, Cuthbertson DJ, Dobson R, GrozinskyGlasberg S, Steeds RP, et al: Diagnosing and managing carcinoid heart disease in patients with neuroendocrine tumors: An expert statement. J Am Coll Cardiol 69: 1288-1304, 2017.

3. Zavras N, Schizas D, Machairas N, Damaskou V, Economopoulos $\mathrm{N}$ and Machairas A: Carcinoid syndrome from a carcinoid tumor of the pancreas without liver metastases: A case report and literature review. Oncol Lett 13: 2373-2376, 2017.

4. Bhattacharyya S, Davar J, Dreyfus G and Caplin ME: Carcinoid heart disease. Circulation 116: 2860-2865, 2007.

5. Comaru-Schally AM and Schally AV: A clinical overview of carcinoid tumors: Perspectives for improvement in treatment using peptide analogs (Review). Int J Oncol 26: 301-309, 2005.

6. Connolly HM, Schaff HV, Abel MD, Rubin J, Askew JW, Li Z, Inda JJ, Luis SA, Nishimura RA and Pellikka PA: Early and late outcomes of surgical treatment in carcinoid heart disease. J Am Coll Cardiol 66: 2189-2196, 2015.

7. Bhattacharyya S, Toumpanakis C, Burke M, Taylor AM, Caplin ME and Davar J: Features of carcinoid heart disease identified by 2- and 3-dimensional echocardiography and cardiac MRI. Circ Cardiovase Imaging 3: 103-111, 2010.

8. Amano Y, Mandai M, Baba T, Hamanishi J, Yoshioka Y, Matsumura N and Konishi I: Recurrence of a carcinoid tumor of the ovary 13 years after the primary surgery: A case report. Oncol Lett 6: 1241-1244, 2013.

9. Pellikka PA, Tajik AJ, Khandheria BK, Seward JB, Callahan JA, Pitot HC and Kvols LK: Carcinoid heart disease. Clinical and echocardiographic spectrum in 74 patients. Circulation 87: 1188-1196, 1993.

10. Mansencal N, Mitry E, Forissier JF, Martin F, Redheuil A, Lepère $\mathrm{C}$, Farcot $\mathrm{JC}$, Joseph $\mathrm{T}$, Lacombe $\mathrm{P}$, Rougier $\mathrm{P}$, et al: Assessment of patent foramen ovale in carcinoid heart disease. Am Heart J 151: 1129.e1-1129.e6, 2006.

11. Zoghbi WA, Adams D, Bonow RO, Enriquez-Sarano M, Foster E, Grayburn PA, Hahn RT, Han Y, Hung J, Lang RM, et al: Recommendations for noninvasive evaluation of native valvular regurgitation. J Am Soc Echocardiogr 30: 303-371, 2017.

12. Haugaa KH, Bergestuen DS, Sahakyan LG, Skulstad H, Aakhus S, Thiis-Evensen E and Edvardsen T: Evaluation of right ventricular dysfunction by myocardial strain echocardiography in patients with intestinal carcinoid disease. J Am Soc Echocardiogr 24: 644-650, 2011.

13. Castillo JG, Silvay G and Solís J: Current concepts in diagnosis and perioperative management of carcinoid heart disease. Semin Cardiothorac Vasc Anesth 17: 212-223, 2013.

14. Mollet NR, Dymarkowski S and Bogaert J: MRI and CT revealing carcinoid heart disease. Eur Radiol 13: L14-L18, 2003.

15. Dobson R, Burgess MI, Pritchard DM and Cuthbertson DJ: The clinical presentation and management of carcinoid heart disease. Int J Cardiol 173: 29-32, 2014.

16. Dobson R, Burgess MI, Valle JW, Pritchard DM, Vora J, Wong C, Chadwick C, Keevi B, Adaway J, Hofmann U, et al: Serial surveillance of carcinoid heart disease: Factors associated with echocardiographic progression and mortality. Br J Cancer 111: 1703-1709, 2014.

17. Tantu M, Belu E, Bobescu E, Armean SM, Armean P, Constantin MM and Domnariu CD: Role of angiotensin converting enzyme (ACE) inhibitors in hypertension and cardiovascular protection management. Farmacia 62: 443-451, 2014.

18. Edwards NC, Yuan M, Nolan O, Pawade TA, Oelofse T, Singh H, Mehrzad H, Zia Z, Geh JI, Palmer DH, et al: Effect of valvular surgery in carcinoid heart disease: An observational cohort study. J Clin Endocrinol Metab 101: 183-190, 2016.

19. Hassan SA, Banchs J, Iliescu C, Dasari A, Lopez-Mattei J and Yusuf SW: Carcinoid heart disease. Heart 103: 1488-1495, 2017. 
20. Pavel ME, Hainsworth JD, Baudin E, Peeters M, Hörsch D, Winkler RE, Klimovsky J, Lebwohl D, Jehl V, Wolin EM, et al; RADIANT-2 Study Group: Everolimus plus octreotide long-acting repeatable for the treatment of advanced neuroendocrine tumours associated with carcinoid syndrome (RADIANT-2): A randomised, placebo-controlled, phase 3 study. Lancet 378: 2005-2012, 2011.

21. Kulke MH, O'Dorisio T, Phan A, Bergsland E, Law L, Banks P, Freiman J, Frazier K, Jackson J, Yao JC, et al: Telotristat etiprate, a novel serotonin synthesis inhibitor, in patients with carcinoid syndrome and diarrhea not adequately controlled by octreotide. Endocr Relat Cancer 21: 705-714, 2014.

22. Connolly HM, Nishimura RA, Smith HC, Pellikka PA, Mullany CJ and Kvols LK: Outcome of cardiac surgery for carcinoid heart disease. J Am Coll Cardiol 25: 410-416, 1995.

23. Manoly I, McAnelly SL, Sriskandarajah S and McLaughlin KE: Prognosis of patients with carcinoid heart disease after valvular surgery. Interact Cardiovasc Thorac Surg 19: 302-305, 2014.

24. Patel C, Mathur M, Escarcega RO and Bove AA: Carcinoid heart disease: Current understanding and future directions. Am Heart J 167: 789-795, 2014

25. Mortelmans P, Herregods MC, Rega F and Timmermans P: The path to surgery in carcinoid heart disease: A retrospective study and a multidisciplinary proposal of a new algorithm. Acta Cardiol: Jun 18, 2018 (Epub ahead of print).

26. Gustafsson BI, Hauso O, Drozdov I, Kidd M and Modlin IM: Carcinoid heart disease. Int J Cardiol 129: 318-324, 2008.

27. Luis SA and Pellikka PA: Carcinoid heart disease: Diagnosis and management. Best Pract Res Clin Endocrinol Metab 30: 149-158, 2016.
28. Arghami A, Connolly HM, Abel MD and Schaff HV: Quadruple valve replacement in patients with carcinoid heart disease. J Thorac Cardiovasc Surg 140: 1432-1434, 2010.

29. Wilhelmi M, Fritz MK, Fischer S, Haverich A and Harringer W: Triple valve replacement in a patient with severe carcinoid heart disease. Cardiovasc Surg 10: 287-290, 2002.

30. Mokhles P, van Herwerden LA, de Jong PL, de Herder WW, Siregar S, Constantinescu AA, van Domburg RT and RoosHesselink JW: Carcinoid heart disease: Outcomes after surgical valve replacement. Eur J Cardiothorac Surg 41: 1278-1283, 2012.

31. Ridker PM, Chertow GM, Karlson EW, Neish AS and Schoen FJ: Bioprosthetic tricuspid valve stenosis associated with extensive plaque deposition in carcinoid heart disease. Am Heart J 121: 1835-1838, 1991.

32. Schaefer A, Sill B, Schoenebeck J, Schneeberger Y, Reichenspurner $\mathrm{H}$ and Gulbins $\mathrm{H}$ : Failing stentless bioprostheses in patients with carcinoid heart valve disease. J Cardiothorac Surg 10: 41, 2015.

33. Heidecker B, Moore P, Bergsland EK, Merrick SH and Rao RK: Transcatheter pulmonic valve replacement in carcinoid heart disease. Eur Heart J Cardiovasc Imaging 16: 1046, 2015.

34. Khan JN, Doshi SN, Rooney SJ, Bhabra MS and Steeds RP: Transcatheter pulmonary and tricuspid valve-in-valve replacement for bioprosthesis degeneration in carcinoid heart disease. Eur Heart J Cardiovasc Imaging 17: 114, 2016.

(i) () (9) This work is licensed under a Creative Commons Attribution-NonCommercial-NoDerivatives 4.0 International (CC BY-NC-ND 4.0) License. 